\title{
Application of Electron and Light Microscope in Evaluate Decay Mechanism of Ancient Glass
}

\author{
Farahnaz Bayatnejad, Mohamadamin Emami*
}

Conservation Faculty. Esfahan Art University, Esfahan, Iran

\begin{tabular}{|c|c|}
\hline Article Info & ABSTRACT \\
\hline Received: 2017/05/25 & Ancient glass, as rare archaeological findings in sites, which clarifying the skill \\
\hline Accepted: 2017/07/28 & and technology of artisans in controlling the furnace heat and know-how about the \\
\hline Published Online 2017/10/29 & raw-mix in glass industry. Due to the glass destruction in burial setting, ancient glass \\
\hline & has different defects depending on its application and the way of use. Destruction \\
\hline & and damages in historic glass happen through the effects of environmental factors on \\
\hline & $\begin{array}{l}\text { surface of the glass or through mass transfer due to changing the conditions from } \\
\text { inside the glass toward the surface (leaching). Non-destructive methods in }\end{array}$ \\
\hline & identifying the structural nature of the objects and the destruction during ages have \\
\hline & $\begin{array}{l}\text { higher priority than other techniques. In this article some historic glass discovered } \\
\text { from the city Istakhr belongs to the early years of Islamic are evaluated. To analyze }\end{array}$ \\
\hline & destructive structures Light Microscope with reflected light and Electron Microscope \\
\hline & $\begin{array}{l}\text { were used. These methods help to identify and analyze surface destruction such as } \\
\text { weathering corrosion and iridescence in order to have a better understanding of }\end{array}$ \\
\hline & corrosion structure and types of damages. \\
\hline
\end{tabular}

Keywords: Glass, Light Microscope, Scanning electron microscope, Iridescence, Weathering, Destruction

Corresponding Information: Conservation Faculty, Esfahan Art University, Esfahan, Iran. Email: m.emami@aui.ac.ir

Copyright $\left({ }_{0}\right.$ 2017, Ir Cons Sci J. This is an open-access article distributed under the terms of the Creative Commons Attribution-noncommercial 4.0 International License which permits copy and redistribute the material just in noncommercial usages, provided the original work is properly cited.

\section{Introduction}

Fars province, capital of two immense Iranian Empires (Achaemenid and Sassanid), due to various and significant objects, this periphery has an important role in archaeological studies. Many remains of cities, castles, hundreds of historical hills and small and big archaeological sites, have made this region - at least in historical periods- the first center of archaeological researches in Iran (Asadi, 2005).

One of the main area located in Pasargad World Heritage Site, is the city "Istakhr". Istakhr is located $5 \mathrm{~km}$ north of Persepolis and this area was a great and importance periphery during the Sassanian Empire as a strategical land. This region is in the beginning of the Valley of Polvar River which the connected Marvdasht and southern regions of Fars with their northern regions and generally with the central parts of Iran plateau. The region is geographically considerable. According to archaeological evidences, Islamic and Sasanian period of Istakhr city is well-studied. Many excavations have been done and even now some are running so by every artistic, cultural and historical finding of this region,
Archaeologists and the researchers in Anthropology get closer to the world of our ancestors. Glassware are examples of the findings of these excavations which are important, not only aesthetically, but also from technology and accessibility to materials and resources point of view. Understanding the structural features of historic glass and the amount of destruction in different burial environment is crucial for interdisciplinary science specialists (Brill, 2005; Brill \& Rising, 1999). In this research some glass fragments from the excavations of the city Istakhr in 1394, are studied. Their defects and destruction forms, such as iridescence effect are investigated by Light Microscopy (LM) and Scanning Electron Microscopy (SEM). Identifying the damages of these objects through non-destructive methods, can be advantageous for conservation of such valuable objects.

According to the Getty conservation institute (2016), glass is: an inorganic and amorphous substance which becomes a super viscous liquid in rapid heating. There are many descriptions for glass such as: "glass is a solid and amorphous (non-crystalline) material which can 
transform from a solid and fragile form to a melt and elastic material" (Burnett, 1986). This behavior is called "glass transfer" and can be observed in amorphous or semi-crystalline materials. Ancient glass consist alkaline silicates, carbonates and some colorings which have been made by melting and forming them in hand or mold (Brill \& Rising, 1999).

\section{Material and Methods}

\subsection{Sample description}

These glass fragments have different colors, some of them with special colors were selected.

\subsubsection{Sample SU 129}

A part of a blue container edge in $3 \mathrm{~cm}$ (Fig 1-A). Weathering and corrosion products have completely covered its surface and in cross sections, ion leaching in microscopic scales can be seen. On this sample iridescence and leaching are clearly visible.

\subsubsection{Sample SU 129-c}

This is a piece of glass with light green belong to a bottle neck (Fig 1-B). The effects of weathering and corrosion can be seen on all its surface.

\subsubsection{Sample SU141}

This is a part of the body in different colors (Fig 1C). This sample has a variety of colors on its surface and its inner parts are green and golden. Iridescence can be seen on the surface.

\subsubsection{Sample SU190}

This sample seems that belong to the bottom of a wide container (Fig 1-D). Corrosion and weathering forms can be easily seen on the external surface. No evidence was found to prove iridescence or exfoliating in this sample.

In order to achieve research's goals, analyzing and evaluating method was divided into two categories: 1-mineralogical studies based on microscopic methods in order to identify crystalline or amorphous phases and 2- identifying secondary phases formed by erosion process and environmental changes. BX61 Polarizing Microscope was used to identify crystalline structures and analyzing minerals, based on petrography of the samples. TESCAN MIRA3 system was used to study the microstructures.
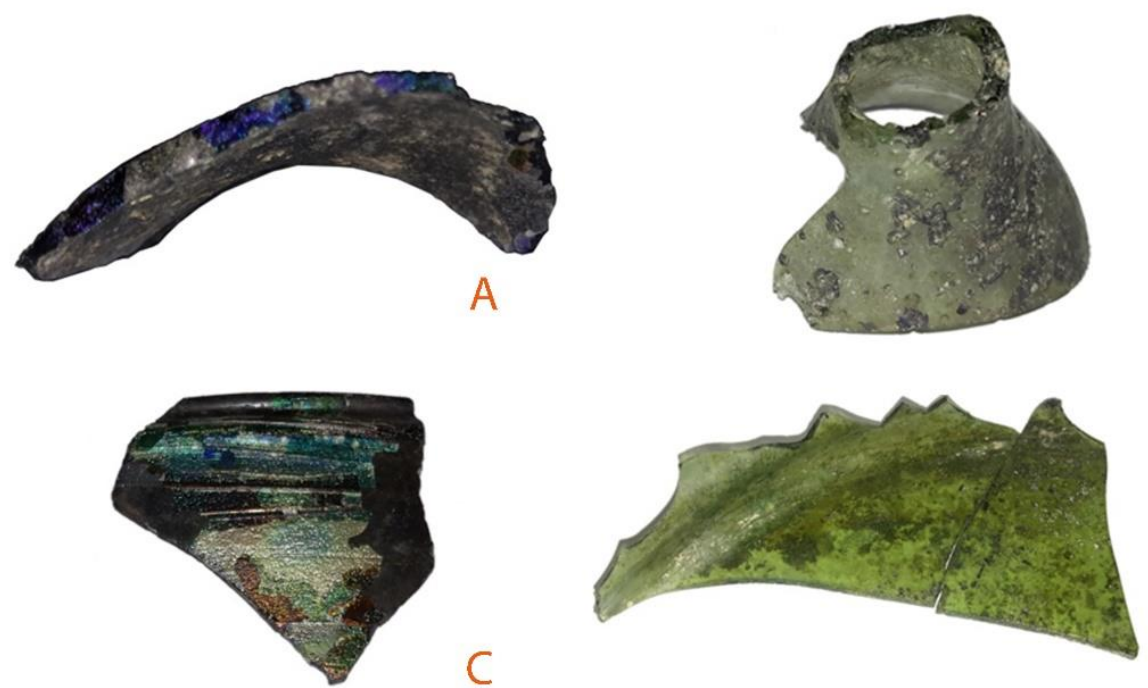

Fig 1. The samples in this article, categorized based on morphological features and color, all of them had Iridescence.

\section{Results and discussion}

\subsection{Investigations of glass thin-sections by means of polarizing Light Microscope}

After polishing making at the cross section of samples; based on the intensity of light reflection of crystalline phases, opaque bubbles with structure similar to a finger print are visible on the edges and on the convex surface's boundaries. These might be the lines of cooling and stiffness of glass viscose liquid in high temperature (sample 129, Fig 2). The leaching of the ions in bright green and compressed forms can be seen on top of the bubbles which are formed during the boiling and cooling process. Rough surface was detected on polished section under the polarized microscope which refers to nonuniform materials. High temperature during fabrication and high viscosity of glass materials which confines gas phase inside the viscose liquid, is responsible for forming mixed bubbles. However the difference in size of the bubbles would suggest that the cooling rate has not been 
steady (Fig 3). On the external edge of the samples, surface alterations, shelly crust, leaching and iridescence can be seen. It can be explained that the contact of these sections with soil have caused the accumulation of alkaline ions in this region and forming exfoliating, lamination and iridescence of glass, consequently (Emami, Nekouei, Ahmadi, Pritzel, Trettin, 2016). The cooling lines in this region have more compaction than other regions.

The cross section of glass is coarse-grained and the cooling process has occurred on the whole surface but the surface of the glass is not completely homogeneous. In such case of liquid cooling, light scattering occurs unevenly and creates shellfish-like bubbles and a colorful scale on its center, subsequently. This uneven scattering of light reflection is known as "Iridescence".

The inner surface of the sample in polished cross section especially in SU129-c is impure and with holes, like other similar historic glass. In external edges, bubbles in shape of snail with yellow, purple and green color can be seen (iridescence of the glass). Polarized microscope detections on SU141 show that the bubbles have $120^{\circ}$ angle, also they are tangent to each other. The leaching and accumulation of ions in jutted part of the convex surface are easily detectable in colors of purple and green (Fig 4). Historic glass is often seen in green because of the presence and accumulation of calcium, phosphorous and iron which have been caused to happen that. The evidences of foliating and the deterioration can be seen on the right and its top (Freestone and Midleton, 1987). Multilayered structure and shelly crust are visible on its whole surface. The lines of cooling and spiral, in central parts of the sample is seen like a mass which can be due to the short time of cooling of the boiling liquid (Fig 5).

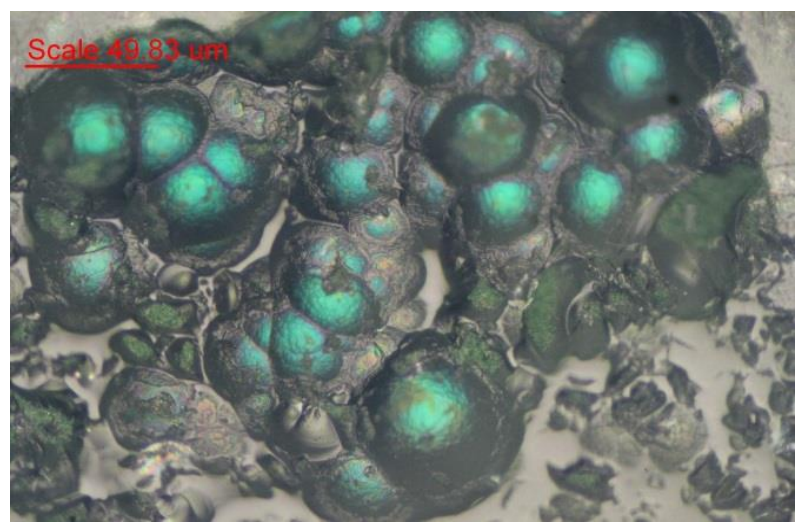

Fig 3. Bubbles of rapid cooling in glass matrix

Fig 2. Finger print structures caused by rapid cooling of sample or glass paste.

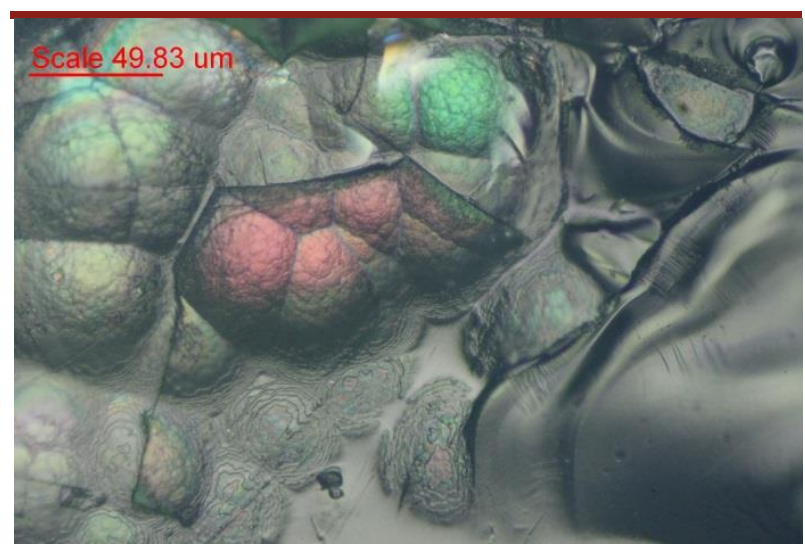

Fig 4. Bubbles with $120^{\circ}$ angle and tangent to each other. The leaching and accumulation of ions and green color can be seen

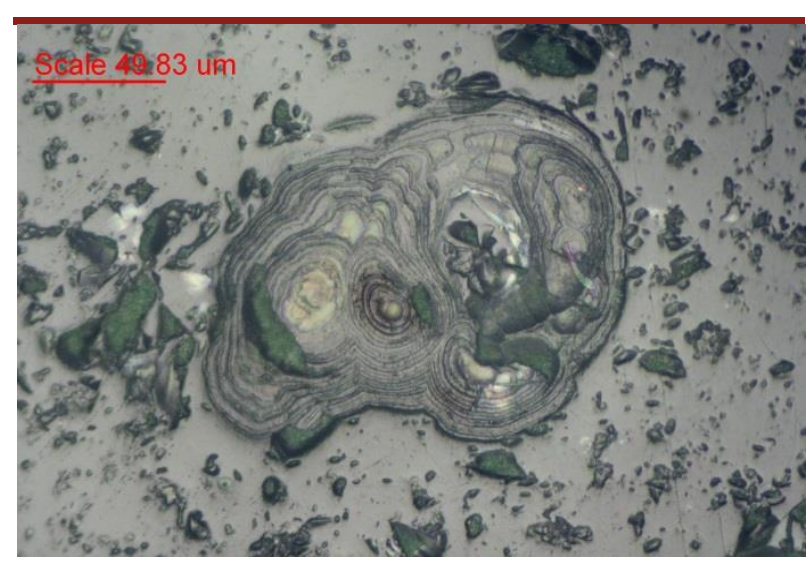

Fig 5. Stiffening line with spiral structures 
Bubbles, emboss parts and spiral structures cannot be seen in SU190 and its surface seems to be smoother than other samples. The only symptom of corrosion in this sample is spectra of different colors such as purple and pink which might be the reflection of polarized light in different angles and consequently make a visual error in observing the colors. This phenomenon is called Iridescence, as discussed before (Fig 6).

\subsection{Scanning Electron Microscope (SEM) detections and analyzing glass structure}

After analyses by Light Microscope, the samples was covered by a thin layer of gold and was studied by Scanning Electron Microscope.

Investigations detected multilayered structure of silicon oxide and glass network formers as well as interspersed bubbles caused by boiling of raw materials and also the trace of the bubbles formed during the cooling process in glass structure (Fig 7). The layers formed over each other, are caused by exfoliating of glass which might be the result of burial environment followed

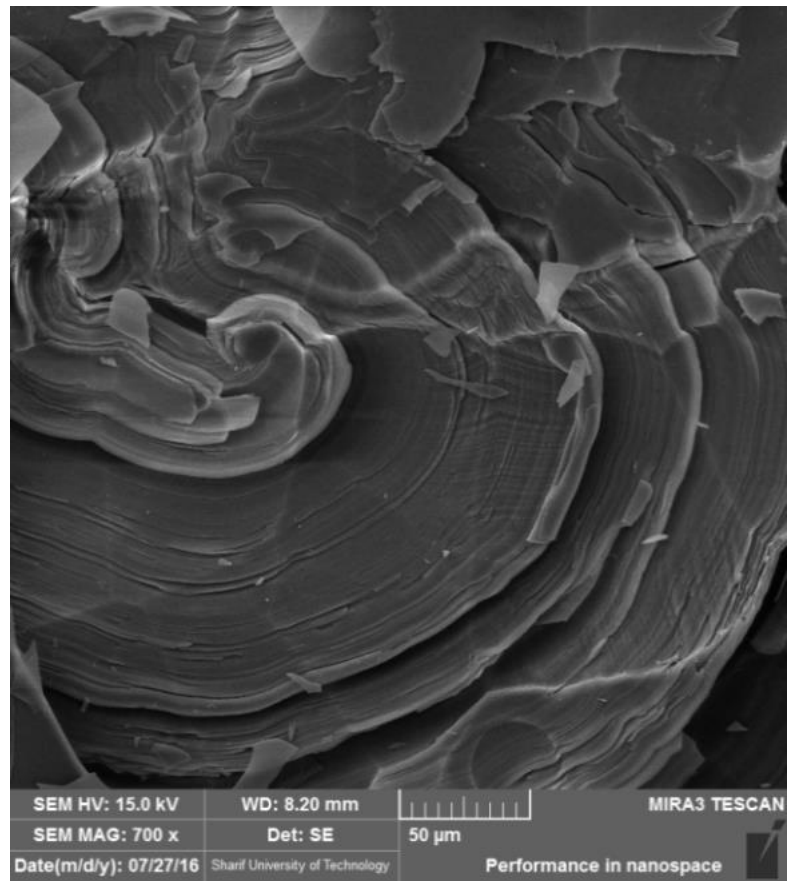

Fig 7. multilayered structures from cooling of glass by Ion leaching over ages. In SU129-c this destruction on the surface can be seen in form of cavities. The bubbles formed in the structure of the glass are result of high boiling temperature and then rapid cooling of the liquid. This phenomenon was not seen in this sample. The detections show clearly the non-uniform surface of glass is and the shelly structure of the surface is in its beginning steps and has not reached to inner layers yet (Fig 8). In the SEM images from SU141 as well as the images taken from polished cross section, the border between bubble structures of the glass and multilayered structures, are clearly visible. The brightness of the borders can be an evidence to accumulation of heavy metal ions and their leaching (Fig 9). In SU190, a smooth surface of the glass with low damage in detectable. This surface is not porous with full of cavities. However compared with other samples the surface is intact. In central parts the structure of glass has less density due to the immigration of ions and the iridescence. In SU190 sampling was done not only from the surface, but also from the cross section of sample and the accumulation of impurities on the edges of two surfaces is clearly visible (Fig 10).

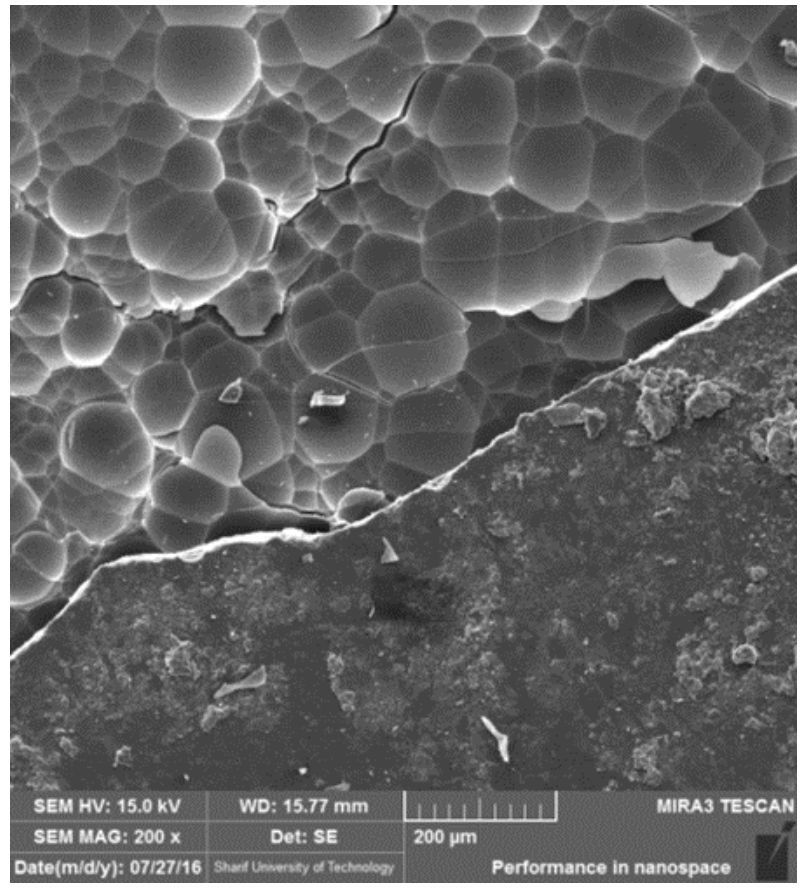

Fig 8. non-uniform surface and shelly crust on glass samples formed over time 


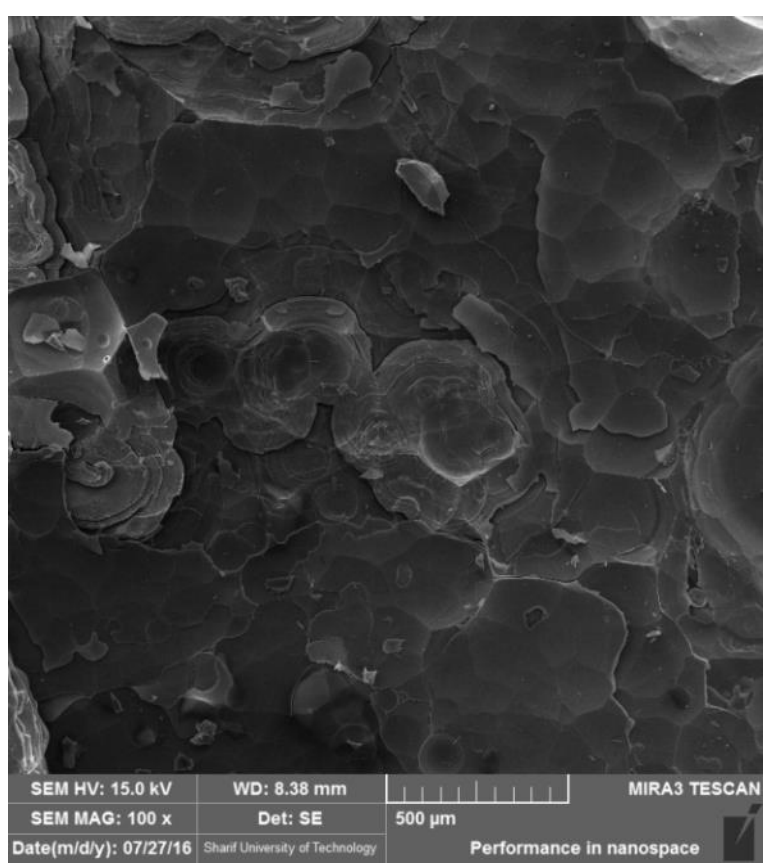

Fig 9. The brightness of the borders of bubbles in glass structure show heavy metal ion accumulation and their leaching

The studies and reviews on a group of similar samples in this study would recommend that this two methods could confirm and be complementary of each other in microscopic perceptions of object's surface. By means of Polarizing Light Microscope (PLM) we can study: external layer and the edge of samples, formation type, the placement of glass component, the angle of glass components formation, the effects of the highest temperature of raw materials, observing concavities and jutting and their angles and cooling and stiffing process. The colors in this type of investigation play a significant role in characterization of material phases in terms of durability and inception of destruction process. Through the high concentration and clarify of colors, it can be detected that destruction and corrosion on their surfaces are existed dtectable more than the other part. This happens where the accumulation and leaching of ions are in a high level (Dararutana \& Sirikulrat, 2007). In the EDAX evaluations through linear scanning, we observed the accumulation of alkaline ions in colors like magnesium and phosphor on the parts mentioned above.

Reviewing the samples after coating by gold, supported our former observations. Furthermore we detected and analyzed inner layers and concave surfaces and cross sections of the samples in these tests. The results distinctly confirm damages like foliated structure and cavities on the surface. In some cases accumulation of impurities and metal oxides was detected in their cross sections.

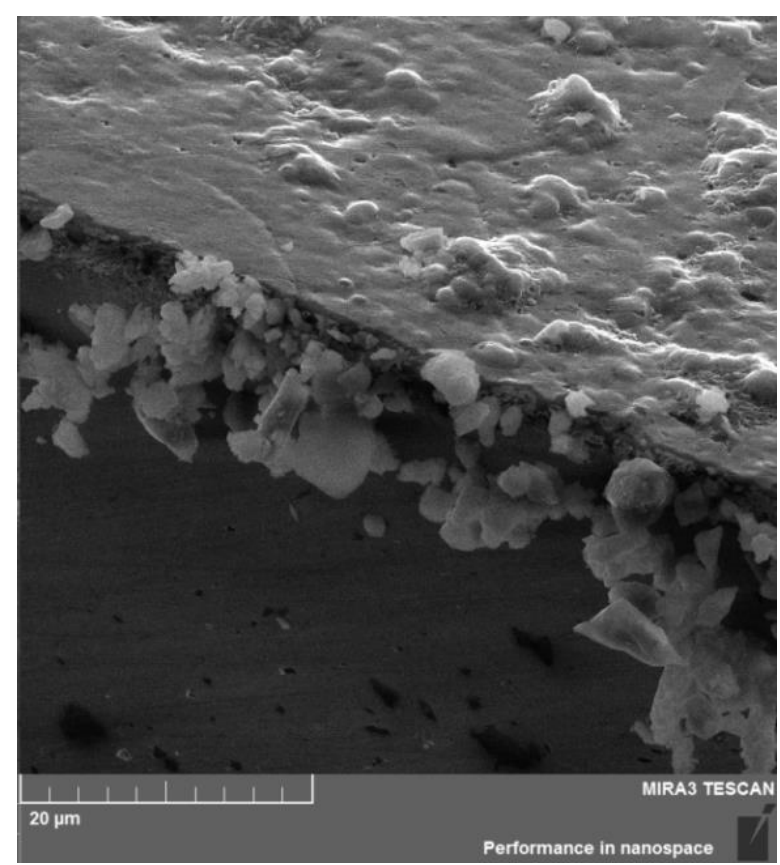

Fig 10. Accumulation of impurities on the edge of the inner and external surface which cause it to be colorful

\section{Conclusion}

In archaeological findings like glasses, destruction processes such as weathering, exfoliating and shelly crust occur in contact with oxygen more quickly. Glass diagnosis by means of Polarizing Light Microscope and Scanning Electron Microscope, can be the beginning measurements in this contexts. These techniques could be used in combination with equipment of element characterization and material phases such as EDAX in order to identify surface destruction of glass, by means of different bulk chemical composition. Through these sort of data we can have a better understanding of the condition of the burial environment of these objects. Through these analytical methods, destruction of the objects and characterization of their surface deformation can be studied. Light microscopy method give some idea on the glass forming crystalline constituents based on their birefringence color. Consequently, scanning electron microscopy is also a useful method in description of the fractional leaching toward to the surface of glasses, and exfoliation which caused during burial conditions in different environment.

\section{Conflict of Interest}

Authors declared no conflict of interest. 


\section{References}

Asadi, A. (2005). An assessment of settlement sequence in Estakhr city according to archaeological evidences. Tehran, Iran: University of Tehran.

Brill, R. H. (2005). Chemical analyses of some Sasanian glasses from Iraq. Sasanian and Post-Sasanian Glass in the Corning Museum of Glass, 2(Appendix), 65-88.

Brill, R. H., Rising, B. A. (1999). Chemical analyses of early glasses: volume 1: the years 1999, reports, and essays. Corning Museum of Glass.

Burnett, J. (1986). The use of new materials in the manufacture of scientific instruments, c. 1880-c. 1920. Ref, 58, 217-238.
Dararutana, P., \& Sirikulrat, N. (2007). Scanning electron microscopy investigation of lead-free high refractive index glass prepared from local sand used for restoration and conservation. Microscopy Book Series, (3).

Emami, M., Nekouei, S., Ahmadi, H., Pritzel, C., \& Trettin, R. (2016). Iridescence in Ancient Glass: A Morphological and Chemical Investigation. International Journal of Applied Glass Science, 7(1), 59-68.

Freestone, I. C., \& Middleton, A. P. (1987). Mineralogical applications of the analytical SEM in archaeology. Mineralogical Magazine, 51(1), 21-31.

How to Cite This Article:

Bayatnejad F, Emami M. Application of Electron and Light Microscope in Evaluate Decay Mechanism of Ancient Glass. Ir Cons Sci J. 2017; 1 (1) :17-22

URL: http://journal.richt.ir/ics/article-1-23-en.html 